\title{
Development of a universal microinfiltrometer to estimate extent and persistence of soil water repellency as a function of capillary pressure and interface chemical composition
}

\author{
Nasrollah Sepehrnia*, Susanne K. Woche, Marc-O. Goebel, Jörg Bachmann \\ Institute of Soil Science, Leibniz Universität Hannover, Herrenhäuser Str. 2, D-30419 Hannover, Germany. \\ *Corresponding author. Tel.: +4951176119250. Fax:+49511762-5559. E-mail: sepehrnia@ifbk.uni-hannover.de
}

\begin{abstract}
Microinfiltrometers to assess soil water repellency (SWR) are limited to small tension ranges and have different technical setups, hindering a comparison between results from different laboratories. Hence, a microinfiltrometer which considers various aspects like extent and persistence of SWR is needed. The technical update suggested here uses glass tubes (e.g., $3 \mathrm{~mm}$ inner diameter), a fabric of mesh size $15 \mu \mathrm{m}$ around the tip to enable good contact between soil surface and tip, ultrapure degassed water, and an evaporation protection for tip and reservoir during long-term infiltration. The adjustment of a continuous range of pressures and tensions (i.e., +0.5 to $-40 \mathrm{~cm}$ ) was done using glass tubes of various lengths connected to the tip. Three soil samples with initial contact angles, CA, of $18^{\circ}, 62^{\circ}$, and $91^{\circ}$ after $25^{\circ} \mathrm{C}$ treatment were additionally treated at $80^{\circ} \mathrm{C}$ to increase SWR persistence and CA. The soil particle interface chemical composition was determined by X-ray photoelectron spectroscopy (XPS). The hydrophysical properties evaluated included water and ethanol sorptivity as well as very important aspects of SWR, i.e. water drop penetration time, water repellency cessation time, repellency index, and modified repellency index. The results derived from the technically modified microinfiltrometer setup showed consistent differences between initial wettability and the water repellency cessation time as a parameter describing the development of SWR with time. The interface O/C ratio as derived from XPS data was negatively correlated with CA $(p<0.05)$, thus proving the close relationship between interface chemistry and wettability. Our findings illustrated a strong positive correlation $\left(R^{2}=0.99, p<0.05\right)$ between sorptivity and $\mathrm{O} / \mathrm{C}$ ratio under $-2 \mathrm{~cm}$ tension which can be considered as the universal tension for different aspects of SWR.
\end{abstract}

Keywords: Ethanol; Infiltration; Interface chemistry; Sorptivity; Thermal treatment; X-ray photoelectron spectroscopy.

\section{INTRODUCTION}

Soil exhibits different levels of water repellency due to the complex nature and the spatial arrangement of hydrophobic moieties at the soil particle interfaces (Beatty and Smith, 2014). More frequent and intensive droughts due to global warming may increase the occurrence of water repellency in soil, which may last for weeks (Dekker et al., 2005; Goebel et al., 2011). Hydrophobic organic compounds in soils are exudates of plant roots, components produced by microbes (Hallett et al., 2003; Lichner et al., 2018) or various hydrophobic humic substances (Tschapek, 1984).

Soil water repellency (SWR), as a transient property of soil particle interfaces, often has high temporal and spatial variability that makes water infiltration measurements and predictions of hydrological processes complex (Bauters et al., 2000; Cosentino et al., 2010; Dekker et al., 2001, 2005; Sepehrnia et al., 2017). An accurate prediction of soil hydraulic properties is difficult as SWR changes over the time of infiltration (Bachmann et al., 2007; Clothier et al., 2000). To get spatial resolution, microinfiltrometers are widely used to estimate SWR on small soil samples such as soil aggregates to reveal small-scale variability of hydraulic and hydrophysical properties of soil in the lab. They began by adopting a design developed by LeedsHarrison et al. (1994) and have developed into different designs (Johnson et al., 2005), including an automated setup (Gordon and Hallett, 2014). A limitation of the original infiltrometer (Leeds-Harrison et al., 1994), which was subsequently adopted to measure SWR (Hallett and Young, 1999) was the use of a sponge tip. This had the advantage of providing good contact with a rough soil surface, but its packing into the infiltrometer tip and variability between manufacturers could affect flow rate and produce erroneous results (personal communication Paul Hallett). Another challenge was the use of varying tip sizes, originally between 1.45 and $2.5 \mathrm{~mm}$ radius (Hallett and Young, 1999; Leeds-Harrison et al., 1994), and then subsequently decreased to $0.4 \mathrm{~mm}$ radius to allow measurements at the root-soil interface (Hallett et al., 2003). The latter was also modified by Orfánus et al. (2014) and Lichner et al. (2013), and later used by Sepehrnia et al. (2016). The automated microinfiltrometer developed by Gordon and Hallett (2014) had a tip of $2.9 \mathrm{~mm}$ in radius to measure SWR with less experimental effort during operation. All proposed microinfiltrometers obey the same physical principle to establish a hydraulic gradient for infiltration (Fig. 1) but support water and ethanol infiltration only over a narrow range of tensions; i.e., 0 to $-7 \mathrm{~cm}$.

Microinfiltrometers currently used for routine measurements do not yet reach tensions greater than $-7 \mathrm{~cm}$, due to the pore size of tip materials and probably air bubble formation due to degassing of water (Hallett et al., 2003; Lichner et al., 2013). Most testing by previous researchers has focused on early time infiltration (e.g., $3 \mathrm{~min}$ ) and small infiltrometer tensions, so that mostly hydrophilic or only the largest pores will conduct water at a hydrophilic or a moderate water repellent state. A narrow range of infiltrometer tensions has two limitations: effects of water conducting pores and their development with time cannot be explored, and hydraulic conductivity estimations from infiltration data at multiple tensions are limited. With the rapid measurement approach deployed in most research, SWR is often assumed to be a transient soil property that disappears 


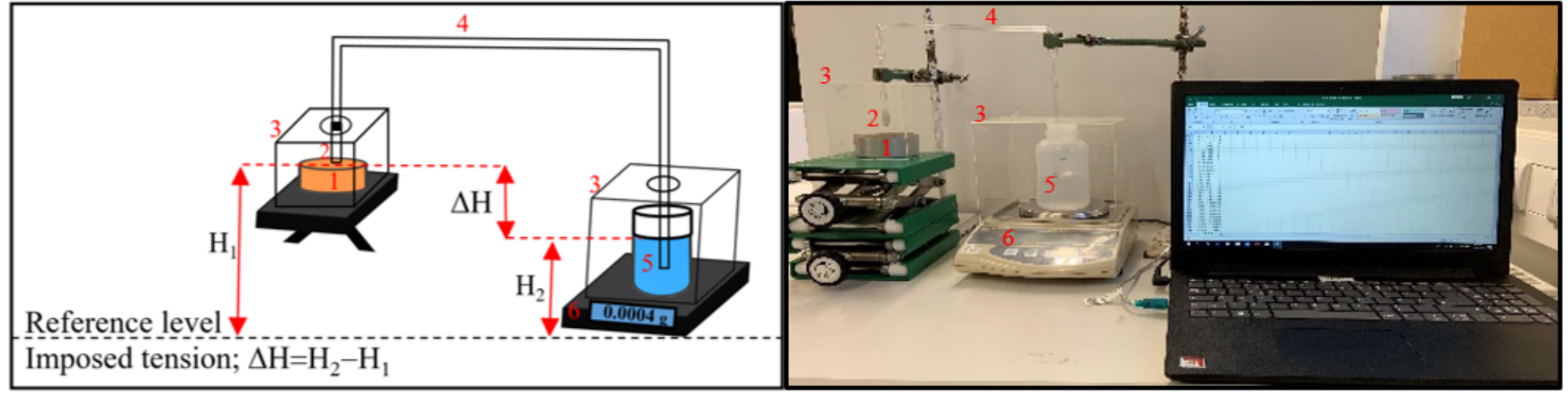

Fig. 1. Microinfiltrometer apparatuses widely used to measure ethanol and water infiltration to estimate the repellency index with updates used in this study. 1 - Steel core with soil sample, 2 - Tip enclosed in fabric (mesh size $0.15 \mu \mathrm{m}$ ), enabling good contact between soil surface and tip. 3 - Plexiglas hood to prevent evaporation during long-term measurement, 4 - Glass tube with inner diameter of $3 \mathrm{~mm}$, 5 - Water or ethanol reservoir, 6 - Four-digit balance. $\mathrm{H}_{1}$ and $\mathrm{H}_{2}$ show the hydraulic potentials of the microinfiltrometer tip and the liquid level, respectively, with respect to the reference level.

after initial infiltration and filling of pores in the contact zone. From the research of Clothier et al. (2000), SWR can take several hours or days to breakdown.

In this study we keep the general microinfiltrometer setup, but we modified some very important technical aspects to allow long-term measurements with either water or ethanol (e.g., 24 h) at a wider range of hydraulic gradients, i.e., from +0.5 to -40 $\mathrm{cm}$. This modified approach addresses longer-term SWR breakdown (Clothier et al., 2000) and more realistic hydraulic conditions regarding capillary pressure in unsaturated soil. It offers to compare common parameters that are used to assess the degree of water repellency under standard conditions (i.e., tension $>-7 \mathrm{~cm}$ ), such as the repellency index under extended infiltration time. In addition, to provide a modified testing apparatus that can be standardized across laboratories, we also provide a standard sample preparation approach. Wetting properties of the soil samples were initially evaluated after drying at $25^{\circ} \mathrm{C}$ (room temperature) and categorized into three groups according to their contact angle as determined by the sessile drop method (Goebel et al., 2013). In this study, soil materials also received thermal treatment at $80^{\circ} \mathrm{C}$. This produced samples with the same texture and carbon content, but increased SWR (i.e., increased CA; Gaj et al., 2019). Such conditions may also be found in natural soils, e.g., in the contact zone of wildfires. The main objectives of this study were i) to update the microinfiltrometer approach technically for a more comprehensive estimation of SWR, ii) to compare repellency indices under an extended range of hydraulic conditions, and iii) to link chemical composition of the interface with micro-hydraulic properties like extent and persistence of SWR. The last step should give the relation between chemical composition of the interface layer and soil hydraulic behaviour. To achieve these objectives, the new infiltrometer was tested against conventional infiltrometers, encompassing a broader range of tensions than could be previously obtained. With the new infiltrometer, tests were conducted over extended periods of time to assess water repellency breakdown. The chemical composition of solid interfaces was used to unravel soil properties that drive SWR behaviour.

\section{MATERIALS AND METHODS \\ Soil samples and studied area}

Soil samples were taken from the beech forest research site Grinderwald $\left(52^{\circ} 49.834^{\prime} \mathrm{N} 10^{\circ} 18.967 ' \mathrm{E}\right)$, located in Lower
Saxony, Germany. Three samples were taken from a soil profile from three depths corresponding to different SWR levels, i.e., water-repellent $(0-5 \mathrm{~cm})$, subcritically water-repellent $(10-20$ $\mathrm{cm})$, and wettable $(20-40 \mathrm{~cm})$. Initial SWR was quantified by CA measurement using the sessile drop method (Bachmann et al., 2003; Goebel et al., 2013). To provide homogeneous samples to allow for repetitive tests, samples were air-dried, sieved $<2$-mm and divided into two portions. One portion of the airdried materials was treated at $25^{\circ} \mathrm{C}$ in a climate-controlled chamber and the other portion was treated at $80^{\circ} \mathrm{C}$ for 24 hours in an oven to emulate a higher level of SWR in conjunction with stronger persistence of SWR (Gaj et al., 2019). The $25^{\circ} \mathrm{C}$ treated material served as reference. Some chemical, physical, and hydrophysical properties of the soil samples are presented in Tables 1 and 2 .

\section{Methods \\ Microinfiltrometer}

The microinfiltrometer follows similar previous designs with a tip that transmits water to the soil that is attached via a tube to a liquid reservoir on a logging balance (Fig. 1). Soil samples are placed on a lab lift to bring the surface into contact with the infiltrometer tip. Key differences to previous designs are the use of mesh fabric at the tip that increases the tension range, a Plexiglas cover for the sample and reservoir to decrease evaporation, and the use of rigid glass tubes to minimize measurement errors. The connecting tube consisted of a 3-mm inner diameter glass U-bend with exchangeable ends for the infiltrometer tip so that tension from $+0.5 \mathrm{~cm}$ to $-40 \mathrm{~cm}$ could be applied. The mesh fabric is commercially used in tension infiltrometers (Product code: 09.09, Eijkelkamp Soil \& Water, The Netherlands) and has a $15 \mu \mathrm{m}$ mesh size with a bubble point of $32 \mathrm{~cm} \mathrm{H}_{2} \mathrm{O}$. The hydraulic conductivity of the tip membrane was $11 \mathrm{~cm} \mathrm{~min}{ }^{-1}$, which is considerably faster than the infiltration rates of most soils. A more detailed description of the different properties of the nylon mesh is listed in the caption of Fig. 1. Preliminary results showed that it is suggested to replace the nylon mesh at the tip after five measurement cycles or clean it using compressed air, because fine soil material could block the mesh.

Ultrapure degassed water was used to reduce air bubble formation in the system and to enable long-time measurements (i.e., $>24 \mathrm{~h}$ ) under higher tensions (i.e., -20 and $-40 \mathrm{~cm}$ ) of the testing liquids; a very important difference to previous approaches (Hallett et al., 2003; Sepehrnia et al., 2016, 2017; Tillman et al., 1989). 
Table 1. Chemical and physical properties of the studied soils presented as mean \pm standard deviation (WS: wettable soil, SRS: subcritically water-repellent soil, RS: water-repellent soil).

\begin{tabular}{|l|c|c|c|c|c|}
\hline Soil & $\begin{array}{c}\text { Depth } \\
(\mathrm{cm})\end{array}$ & $\begin{array}{c}\text { OC } \\
(\%)\end{array}$ & $\begin{array}{c}\text { Clay } \\
(\%)\end{array}$ & $\begin{array}{c}\text { Silt } \\
(\%)\end{array}$ & $\begin{array}{c}\text { Sand } \\
(\%)\end{array}$ \\
\hline WS & $20-40$ & $0.04( \pm 0.03)$ & $1.9( \pm 0.3)$ & $38.9( \pm 0.3)$ & $59.1( \pm 0.61)$ \\
\hline SRS & $10-20$ & $2.52( \pm 0.15)$ & $4.5( \pm 0.2)$ & $34.1( \pm 0.1)$ & $61.4( \pm 0.29)$ \\
\hline RS & $0-5$ & $10.10( \pm 0.58)$ & $6.4( \pm 0.4)$ & $21.6( \pm 3.12)$ & $72.0( \pm 2.7)$ \\
\hline
\end{tabular}

$\mathrm{OC}=$ organic carbon content.

Table 2. The results of water sorptivity $\left(S_{w}\right)$ and unsaturated hydraulic conductivity $\left(K_{h}\right)$, presented as mean \pm standard deviation, measured using a standard infiltrometer (diameter: $31.8 \mathrm{~mm}$, tension: $-0.5 \mathrm{~cm}$, Decagon, USA) to validate the developed microinfiltrometer. Tested were soils (WS: wettable soil, SRS: subcritically water-repellent soil, RS: water-repellent soil) treated at $25^{\circ} \mathrm{C}$ and at $80^{\circ} \mathrm{C}$.

\begin{tabular}{|l|c|c|c|c|c|c|}
\hline \multirow{2}{*}{$\begin{array}{l}\text { Treatment } \\
\text { temperature }\end{array}$} & \multicolumn{3}{|c|}{$S_{w}\left(\mathrm{~cm} \mathrm{~s}^{-0.5}\right)$} & \multicolumn{3}{c|}{$K_{h}\left(\mathrm{~m} \mathrm{day}^{-1}\right)$} \\
\cline { 2 - 7 } & WS & SRS & RS & WS & SRS & RS \\
\hline $25^{\circ} \mathrm{C}$ & $0.140( \pm 0.023)$ & $0.440( \pm 0.01)$ & $0.047( \pm 0.041)$ & $1.10( \pm 0.06)$ & $3.84( \pm 0.93)$ & $0.734( \pm 0.104)$ \\
$80^{\circ} \mathrm{C}$ & $0.143( \pm 0.015)$ & $0.110( \pm 0.02)$ & $0.036( \pm 0.01)$ & $1.10( \pm 0.28)$ & $2.05( \pm 0.63)$ & $0.261( \pm 0.01)$ \\
\hline
\end{tabular}

Water and ethanol (Normapur, 96 vol-\%, VWR Chemicals, France) infiltration tests were performed under different slight pressures $(+0.5$ and $0 \mathrm{~cm})$ as well as under different tensions $(-2,-5,-20,-40 \mathrm{~cm})$ on soil cores repacked to their field bulk density. All experiments were conducted in triplicate. The respective time of each infiltration experiment varied as it depended on soil wetting properties, liquid type, and imposed hydraulic conditions (Table 2). Disturbed soil material was chosen to reduce the natural soil heterogeneity for this evaluation, as the present study focuses on the technical capabilities of the new infiltrometer.

\section{Repellency index}

To estimate the extent of SWR under different tensions, we compared the conventional repellency index $R I$ approach (Eq. (1)) of Tillman et al. (1989), to the modified SWR index defined by Sepehrnia et al. (2016), $R I_{m}$ (Eq. (2)):

$R I=S_{e}\left(h_{0}\right) / S_{w}\left(\mathrm{~h}_{0}\right)$

$R I_{m}=S_{w w}\left(h_{0}\right) / S_{w h}\left(h_{0}\right)$

In Eqs. (1) and (2) $S_{e}$ and $S_{w}$ are ethanol and water sorptivities and $S_{w w}$ and $S_{w h}$ are water sorptivities for hydrophilic and hydrophobic wettability states of the respective samples during the infiltration process. Eq. (2) considers also infiltration under hydraulic pressure $\left(h_{0} ;+0.5\right.$ and $\left.0 \mathrm{~cm}\right)$ or tension $(-2,-5,-20$, and $-40 \mathrm{~cm}$ ) conditions. Only tensions close to zero (i.e., -2 and $-7 \mathrm{~cm}$ ) have been considered in most previous studies (Alagna et al., 2019; Lichner et al., 2013; Tillman et al., 1989).

When the initial SWR in dry soil is not stable and decreases with infiltration time, the conventional procedure (Eq. (1)) gives information on the initial stage of water repellency. Corresponding estimates may overestimate the general water repellency state during the infiltration process after the initial contact with water (Alagna et al., 2019). The $R I_{m}$ (Eq. (2)) overcomes this limitation because it can be used to estimate the water repellency cessation time, WRCT, as an additional and very important characteristic feature of SWR. The WRCT is estimated from the point of intersection of two straight lines, representing the $I=f(\sqrt{t})$ relationship, where $I$ and $t$ are cumulative infiltration and time, for transient water repellency changing to a state of wettability (Lichner et al., 2013; Sepehrnia et al. 2016). The water sorptivity $S_{w h}\left(h_{0}\right)$ for hydrophobic states was estimated from the slope of the "hockey-stick-like" relationship $I=f(\sqrt{t})$, measured under tension or positive pressure $\left(h_{0}\right.$ and $\left.P_{0}\right)$ after the beginning of the infiltration, represented by a straight line showing the less steep part of the hockey stick. If a steeper part of the infiltration characteristics $I=f(\sqrt{t})$ is observed after a longer time, the corresponding WRCT can be determined. This potentially steeper branch of the water sorptivity graph provides an estimate of the $S_{w w}\left(h_{0}\right)$ (Lichner et al., 2013; Sepehrnia et al., 2016).

\section{Water drop penetration time and sessile drop method}

Water drop penetration time, WDPT, was used to evaluate the persistence of water repellency of the studied samples (Dekker and Ritsema, 1994; Letey et al., 2000). It tests the stability of hydrophobic soil conditions with time. The WDPT method consists of placing a drop of water on the soil surface and recording the time required for its complete penetration. Penetration is assumed to start when the solid-liquid CA is $<90^{\circ}$. We placed ten drops of ultrapure water $(35 \pm 5 \mu \mathrm{L})$ onto the horizontal soil surface from a standard height $(10 \mathrm{~mm})$ above the surface, and the time required for infiltration of each drop was recorded (Dekker and Ritsema, 1994; Lichner et al., 2013).

Air-liquid-solid CAs of the studied soils were directly measured by the sessile drop method using a CCD-equipped CA microscope (OCA 15, DataPhysics, Filderstadt, Germany; Goebel et al., 2013). CA of untreated and heat-treated samples was measured by placing water drops (drop volume $1 \mu \mathrm{L}$ ) onto a dense one-grain layer fixed with a double-sided adhesive tape on a microscope slide. CA was measured almost instantaneously after the drop had stabilized (initial CA) and again after 5 seconds (Bachmann et al., 2003; Goebel et al., 2013). This measurement was also conducted after infiltration at the applied pressures/tensions $\left(\mathrm{CA}_{\text {infil }}\right)$. A small sample was taken at the wetted tip area $\left(\sim 1 \times 1 \mathrm{~cm}^{2}\right)$ from a depth of $0-1.5 \mathrm{~cm}$. The samples were shock-frozen by dipping polyethylene containers with the sample material for 10 seconds in liquid nitrogen $\left(-196^{\circ} \mathrm{C}\right)$, followed by freeze-drying to preserve the orientation of hydrophilic and hydrophobic functional groups of the particle interfaces during infiltration (Mao et al., 2019; Thieme et al., 2016). 
Development of a universal microinfiltrometer to estimate extent and persistence of soil water repellency

\section{Microinfiltrometer validation}

Independent water infiltration tests were conducted under $-0.5 \mathrm{~cm}$ tension using a standard infiltrometer (Decagon, 2007) with a bigger contact area $\left(7.92 \mathrm{~cm}^{2}\right)$ to compare with our new microinfiltrometer. The first-term of the Philip infiltration equation (Philip, 1957) was fitted to the cumulative infiltration data:

$\mathrm{I}=\mathrm{C}_{1} t^{1 / 2}+\mathrm{C}_{2} t+\mathrm{C}_{3} t^{3 / 2}+\mathrm{C}_{4} t^{2}+\ldots+\mathrm{C}_{\mathrm{m}} t^{\mathrm{m} / 2}+\ldots$

where $t$ is time and $\mathrm{C}_{1}, \mathrm{C}_{2}, \mathrm{C}_{3}, \mathrm{C}_{4}, \ldots$, and $\mathrm{C}_{\mathrm{m}}$ are coefficients of the series expansion. This enables the calculation of unsaturated hydraulic conductivity $\left(K_{h}\right)$ (Eq. (5)) and the estimation of water sorptivity of the studied soils (Eq. (6)) under $-0.5 \mathrm{~cm}$ tension as proposed by Zhang (1997) with regard to the twoterm form of Philip's equation:

$\mathrm{I}=\mathrm{C}_{1}\left(h_{0}\right) t^{1 / 2}+\mathrm{C}_{2}\left(h_{0}\right) t$

$k\left(h_{0}\right)=\mathrm{C}_{2}\left(h_{0}\right) / \mathrm{A}_{2}$

and

$S\left(h_{0}\right)=\mathrm{C}_{1}\left(h_{0}\right) / \mathrm{A}_{1}$

where $A_{1}$ and $A_{2}$ are dimensionless coefficients which are considered to be 5.3 for the standard infiltrometer (Decagon, 2007) according to Zhang (1997).

\section{Evaluation of interface chemical composition}

Interface chemical composition of selected samples was determined by X-ray photoelectron spectroscopy, XPS, using an Axis Ultra DLD device (Kratos Analytical, Manchester, UK; monochromated $\mathrm{Al} \mathrm{K}_{\alpha}$ radiation at $20 \mathrm{~mA}$ and $12 \mathrm{kV}$ ). Recorded were survey spectra and C 1s detail scans. Quantification of the survey scans (Vision 2, Kratos Analytical, Manchester, UK) gave the interface chemical composition in atomic-\% (at.-\%). C speciation was performed in two ways by either fitting the survey $\mathrm{C} 1 \mathrm{~s}$ peak in a basic procedure with two peaks (polar, $\mathrm{C}_{\mathrm{p}}$, and non-polar, $\mathrm{C}_{\mathrm{np}}, \mathrm{C}$ species; Woche et al. 2017) or fitting the $\mathrm{C} 1 \mathrm{~s}$ detail scan with four sub-peaks, representing $\mathrm{O}=\mathrm{C}-\mathrm{O}$; $\mathrm{O}=\mathrm{C}-\mathrm{N}$ at $289.3 \mathrm{eV}(\mathrm{C} 1$, polar bond $), \mathrm{C}=\mathrm{O}$; $\mathrm{O}-\mathrm{C}-\mathrm{O}$ at 287.8 $\mathrm{eV}$ (C2, polar bond), $\mathrm{C}-\mathrm{O} ; \mathrm{C}-\mathrm{N}$ at $286.4 \mathrm{eV}(\mathrm{C} 3$, partly polar bond), and $\mathrm{C}-\mathrm{C} ; \mathrm{C}-\mathrm{H}$ at $284.8 \mathrm{eV}$ (C4, nonpolar bond) (Gerin et al., 2003). The selection of samples tested by XPS allowed to compare interface chemical composition before and after thermal treatment (air-dry samples) and after wetting during infiltration (shock-frozen and freeze-dried samples) in conjunction with $\mathrm{CA}$ and water sorptivity. For each sample, spectra were recorded at three different spots, comprising an area of $0.21 \mathrm{~mm}^{2}$ each.

\section{Data analysis}

The experiment was performed using a complete randomized design with three replications for all variables. The independent variables were the wetting properties (wettable, subcritically water-repellent, and water-repellent), the thermal treatments $\left(25^{\circ} \mathrm{C}\right.$ and $\left.80^{\circ} \mathrm{C}\right)$ of the soil, and applied pressures/tensions $(+0.5,0,-2,-5,-20$, and $-40 \mathrm{~cm})$ of the infiltrating water from the infiltrometer. The dependent parameters included CA, $R I, R I_{m}, S_{w}, S_{e}$, WRCT, and interface chemical composition $(\mathrm{O} / \mathrm{C}$ ratio, the amount of non-polar $\mathrm{C}$ compounds $\mathrm{C}_{\mathrm{np}}$, and the interface $\mathrm{C} / \mathrm{N}$ ratio). Statistical analyses were done using two-way ANOVA (R Core Team, 2013) and the post-hoc mean comparisons were performed by the LSD test $(p<0.05)$.

\section{RESULTS AND DISCUSSION \\ Technical features of the microinfiltrometer}

A few preliminary remarks outline some features of the new system in comparison to existing microinfiltrometers. Early tests showed that due to very small water flow rates, infiltration measurements are not advisable for very coarse sand textures in combination with tensions $<-20 \mathrm{~cm}$ within a reasonable time span. It was assumed that insufficient hydraulic contact between the tip and soil caused a disruption of water films at the soil-tip contact zone (data not shown). Corresponding disconnected water films in partly saturated water repellent media have been visualized by Muehl et al. (2012). Capillary barrier effects were also evident at the interface between the tip and soil, a well-known effect that occurs in layered wettable media, e.g., a fine-textured layer above a coarse textured soil layer $(\mathrm{Li}$ et al., 2014). However, regardless of the water repellency status and applied tensions, our experiments proved that infiltration into the sandy loam worked well (Table 3 ).

The values of $K_{h}$ measured by the infiltrometer were $1.90 \mathrm{~m}$ day $^{-1}$ for the wettable soil (at $25^{\circ} \mathrm{C}$ ) under zero tension, using Zhang (1997)'s method, which was in agreement with Leeds-Harrison and Youngs (1997) who measured a soil with similar texture. Independent tests using the minidisk infiltrometer (Decagon, 2007) with a significantly bigger contact area ( 7.92 vs. $0.071 \mathrm{~cm}^{2}$ ) at tension of $-0.5 \mathrm{~cm}$ also found good agreement with our new microinfiltrometer design (Table 3). The results of water sorptivity and $K_{h}$ under zero tension were also comparable with observations from Leeds-Harrison et al. (1994) and Leeds-Harrison and Youngs (1997) who used a microinfiltrometer with a $2.9 \mathrm{~mm}$ diameter tip. Their results for a fine sand under zero tension were $S_{w}=0.255 \mathrm{~cm} \mathrm{~s}^{-0.5}$ and $K_{h}=$ $3.76 \mathrm{~m} \mathrm{day}^{-1}$, which are comparable to $S_{w}=0.220 \mathrm{~cm} \mathrm{~s}^{-0.5}$ and $K_{h}=1.30 \mathrm{~m} \mathrm{day}^{-1}$ that we measured for the wettable Grinderwald soil treated at $25^{\circ} \mathrm{C}$ (sand content $=59.1 \pm 0.6 \%$, $\mathrm{CA}=18^{\circ}$ ).

Table 3. The time ( $\mathrm{min}$ ), presented as mean \pm standard deviation, when water begins to infiltrate into the studied soils (WS: wettable soil, SRS: subcritically water-repellent soil, RS: water-repellent soil).

\begin{tabular}{|c|c|c|c|c|c|c|}
\hline \multirow{2}{*}{$\begin{array}{c}\text { Treatment temperature } \\
\text { Pressure/tension }(\mathrm{cm})\end{array}$} & \multicolumn{2}{|c|}{ WS } & \multicolumn{2}{|c|}{ SRS } & \multicolumn{2}{c|}{$\mathrm{RS}$} \\
\cline { 2 - 7 } & $25^{\circ} \mathrm{C}$ & $80^{\circ} \mathrm{C}$ & $25^{\circ} \mathrm{C}$ & $80^{\circ} \mathrm{C}$ & $25^{\circ} \mathrm{C}$ & $80^{\circ} \mathrm{C}$ \\
\hline+0.5 & $0.08( \pm 0.00)$ & $0.08( \pm 0.00)$ & $0.08( \pm 0.00)$ & $0.17( \pm 0.00)$ & $0.17( \pm 0.00)$ & - \\
0 & $0.08( \pm 0.00)$ & $0.08( \pm 0.00)$ & $0.08( \pm 0.00)$ & $0.17( \pm 0.00)$ & $0.14( \pm 0.05)$ & $158.0( \pm 93.00)$ \\
-2 & $0.08( \pm 0.00)$ & $0.08( \pm 0.00)$ & $0.08( \pm 0.00)$ & $0.22( \pm 0.05)$ & $0.33( \pm 0.32)$ & $398.50( \pm 231.10)$ \\
-5 & $0.08( \pm 0.00)$ & $0.08( \pm 0.00)$ & $0.11( \pm 0.05)$ & $0.22( \pm 0.05)$ & $3.20( \pm 4.82)$ & - \\
-20 & $0.14( \pm 0.05)$ & $0.19( \pm 0.05)$ & $0.36( \pm 0.05)$ & $2.30( \pm 1.10)$ & $1.61( \pm 1.14)$ & - \\
-40 & $0.11( \pm 0.05)$ & $0.22( \pm 0.05)$ & $50.30( \pm 43.10)$ & $26.10( \pm 28.50)$ & $21.36( \pm 26.80)$ & - \\
\hline
\end{tabular}


A significant difference to existing infiltrometer devices, technically realized by using the membrane at the tip and degassed ultrapure water, was the ability to extend the range of applied tensions beyond the limitation of $-10 \mathrm{~cm}$ of previous microinfiltrometer studies (Hallett et al., 2003; Lichner et al., 2013; Sepehrnia et al., 2016). However, the use of tensions more negative than $-60 \mathrm{~cm}$ was not possible for long-term experiments, particularly for the water-repellent soil (data not shown). Capillarity was likely disrupted from evaporation and instability and it is possible that the surface tension of the infiltrating liquid decreased due to dissolved organic compounds, thus leading to air entry points of the porous membrane at less capillary pressure (closer to zero). Moreover, slow flow rates may have caused the tip to dry, due to evaporation, leading to air invasion.

Rigid tubes for the entire microinfiltrometer setup improved earlier designs where components were connected with flexible tubes (Hallett et al., 2003; Lichner et al., 2013). When using flexible tubes, fluctuations in recorded data of water infiltration at different tensions occurred within a day, possibly caused by slight mechanical disturbances transferred to the elastic properties of the flexible tube (data not shown). By using a Plexiglas hood to protect the tip and water/ethanol reservoir, losses due to evaporation became insignificant, which was particularly important for tensions more negative than $-5 \mathrm{~cm}$ with the accompanying longer measurement times.

The microinfiltrometer was also robust for ethanol infiltration for all tested pressures and tensions because a big advantage of glass tubes is the avoidance of chemical reactions with the flexible tube material (discoloration) or Plexiglas (cracking) (Evonik, 2000).

\section{Water and ethanol sorptivity}

The values of $S_{w}$ ranged from $0.0041( \pm 0.007)$ to 0.275 $( \pm 0.0091) \mathrm{cm} \mathrm{s}^{-0.5}$ and $S_{e}$ ranged from $0.019( \pm 0.003)$ to 0.383 $( \pm 0.0091) \mathrm{cm} \mathrm{s}^{-0.5}$ (Fig. 3). These values agree with the ranges reported by Lichner et al. (2013) for pure sand $\left(S_{w}: 0.293-1.17\right.$ $\left.\mathrm{cm} \mathrm{s}^{-0.5}, S_{e}: 0.099-0.398 \mathrm{~cm} \mathrm{~s}^{-0.5}\right)$. $S_{w}$ and $S_{e}$ differed between soils $(p<0.05)$, and were influenced by pressures/tensions $(p<0.001)$. Thermal treatments affected $S_{w}(p<0.05)$, particu- larly at higher tensions $(<-5 \mathrm{~cm}$, Fig. 2$)$, but $S_{e}$ did not vary. Greater soil organic carbon (OC) affected $S_{w}$ and $S_{e}$ (Fig. 2), with subcritically water-repellent soil with the greater OC content having a higher sorptivity compared to the wettable soil at $25^{\circ} \mathrm{C}$. In turn, the water-repellent soil with greater OC content and greater CA showed slightly reduced $S_{w}$ compared to the subcritically water-repellent soil. This behaviour, likely driven by the quality and quantity of OC, was clearly observed in the $S_{e}$ data (Table 1, Fig. 2) as ethanol wets soil regardless of wettability. $S_{e}$ could possibly be affected by slight modifications of the particle surfaces (e.g. swelling due to reaction of ethanol and organic particle coating compounds), but these impacts are small compared to the impacts of SWR on $S_{w}$. Therefore, the changes of $S_{e}$ were mainly affected by soil pore size and applied pressures/tensions if variables are compared in Fig. 2.

\section{Persistence, extent, and water repellency cessation time (WRCT)}

The SWR parameters including persistence, extent, and WRCT are presented in Figs. 3, 4, and 5, respectively.

There was no significant change in the persistence of SWR (WDPT $<1 \mathrm{~s}$ ) of wettable soil after $80^{\circ} \mathrm{C}$-treatment, while $80^{\circ} \mathrm{C}$-treatment increased WDPT distinctly for the subcritically water-repellent and the water-repellent soils (Fig. 3). This was consistent with CA analysis that indicated no change in CA for the wettable soil and a distinct CA increase for the subcritically water-repellent and the water-repellent soils after $80^{\circ} \mathrm{C}$ treatment (Fig. 3). At the same time, CA stability increased after $80^{\circ} \mathrm{C}$-treatment, with $\mathrm{CA}>125^{\circ}$ for the water-repellent soil and $70^{\circ}$ for the subcritically water-repellent soil after five seconds, compared to $58^{\circ}$ and $17^{\circ}$ after $25^{\circ} \mathrm{C}$-treatment, respectively. The wettable soil, however, showed no effect. This behaviour fitted well with the observed increase in WDPT (Fig. 3). Bachmann et al. (2003) found WDPT to be sensitive only within a narrow CA range around $90^{\circ}$. Leelamanie et al. (2008) also examined wettable to extremely water-repellent fine sand and reported that the WDPT was $<1 \mathrm{~s}$ for CAs ranging from $11^{\circ}$ to $69^{\circ}$, between $1 \mathrm{~s}$ and $3600 \mathrm{~s}$ for CA from $69^{\circ}$ to $93^{\circ}$, and then exceeded $3600 \mathrm{~s}$ for larger CAs. Leelamanie

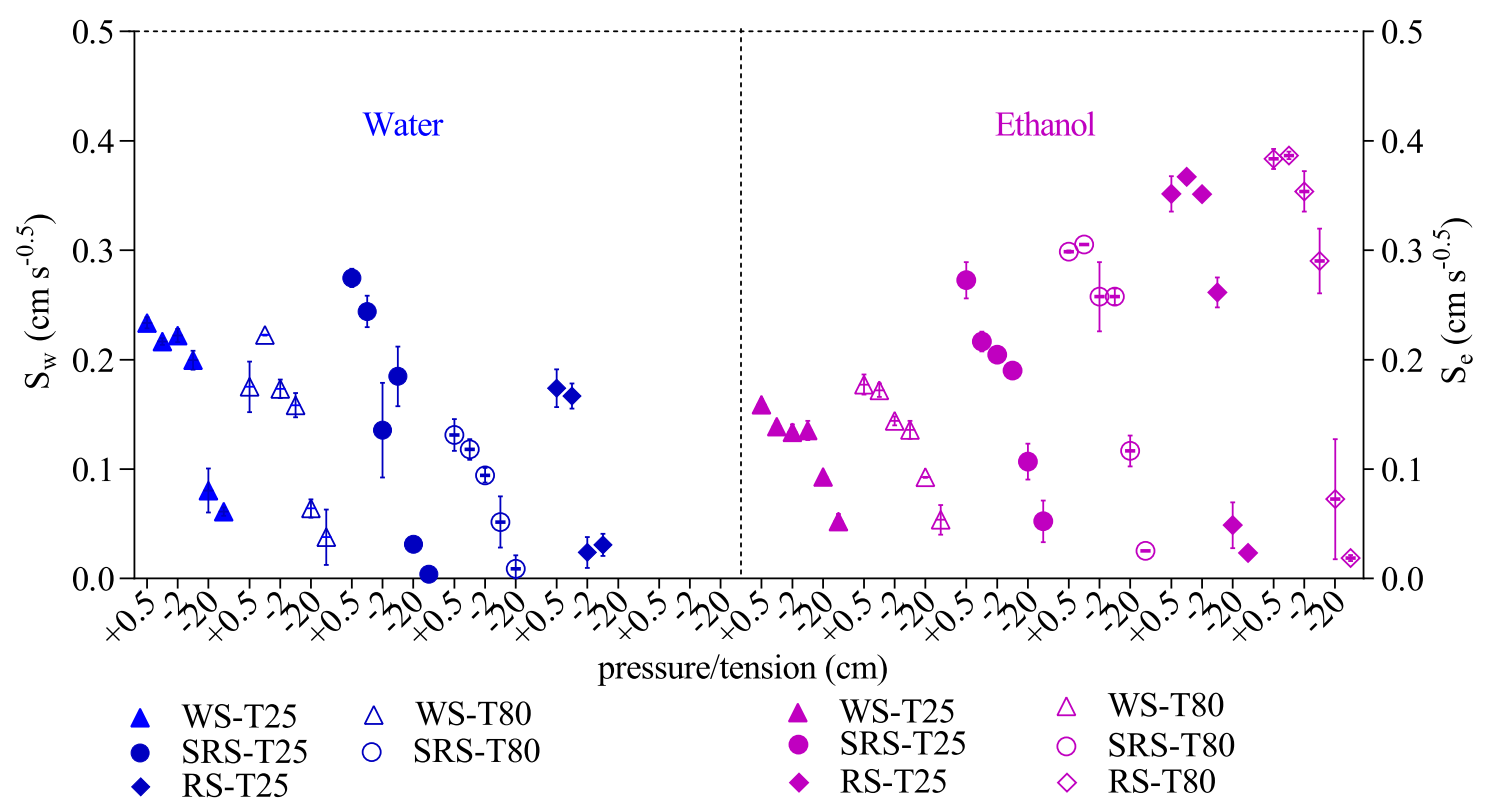

Fig. 2. Water and ethanol sorptivities ( $S_{w}$ and $S_{e}$, respectively) during infiltration for $25^{\circ} \mathrm{C}$ - and $80^{\circ} \mathrm{C}$-treated soils (WS: wettable soil, SRS: subcritically water-repellent soil, RS: water-repellent soil) under different imposed pressures/tensions. 


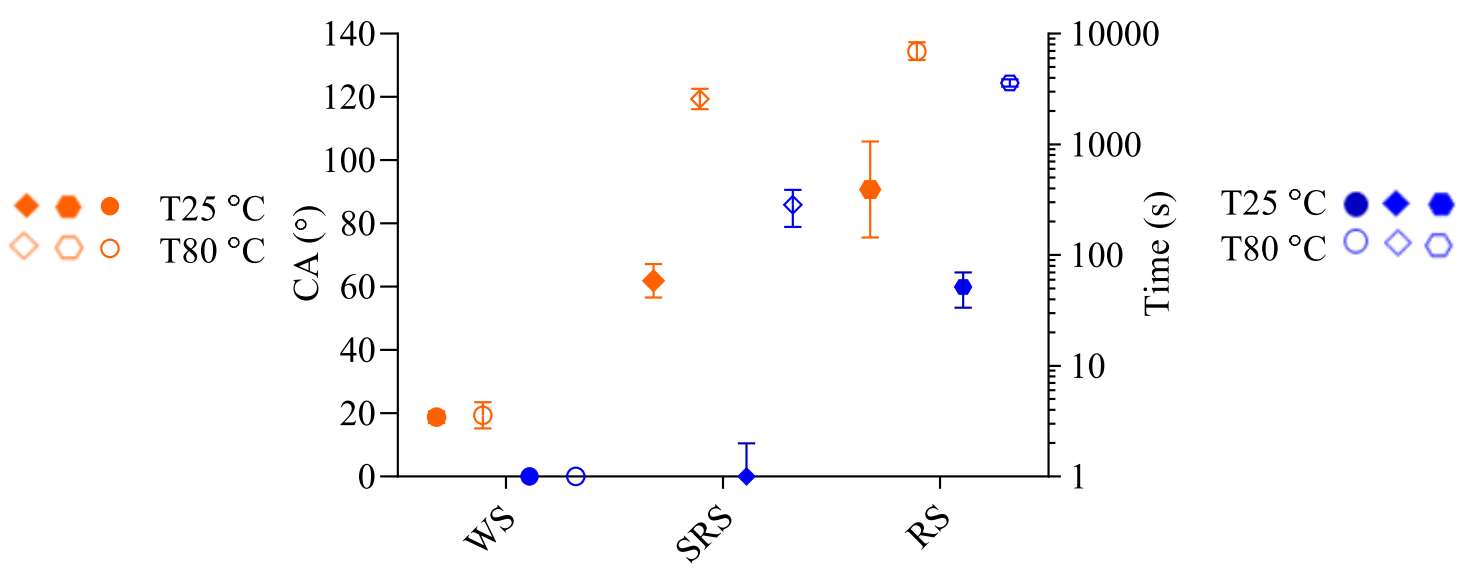

Fig. 3. SWR persistence of the studied soils, quantified by the contact angle, CA (left) and the water drop penetration time, WDPT (right), for $25^{\circ} \mathrm{C}$ - and $80^{\circ} \mathrm{C}$-treated soils (WS: wettable soil, SRS: subcritically water-repellent soil, RS: water-repellent soil).

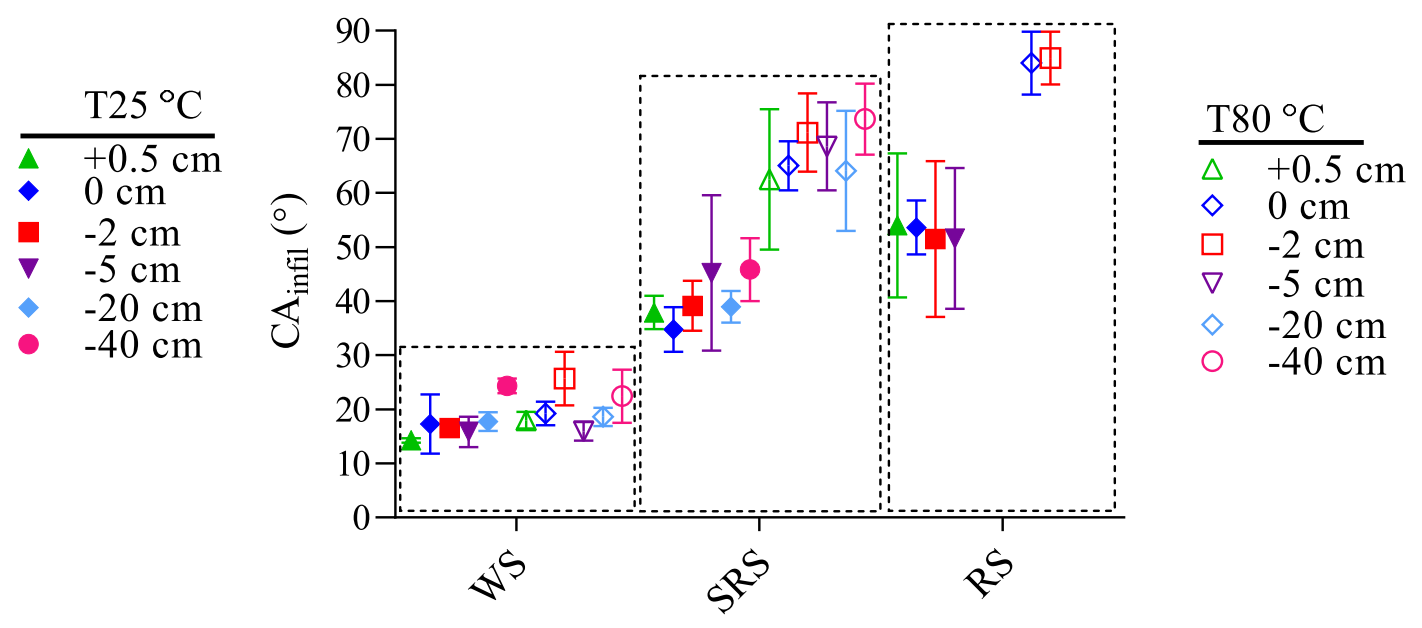

Fig. 4. Contact angle after water infiltration, $\mathrm{CA}$ infil, for $25^{\circ} \mathrm{C}$ - and $80^{\circ} \mathrm{C}$-treated soils under different imposed hydraulic pressures/tensions. The soils are wettable soil (WS), subcritically water-repellent soil (SRS) and water-repellent soil (RS).

et al. (2008) found that the WDPT was most sensitive for CA within the range of $88-93^{\circ}$. Therefore, the evaluation of the persistence of SWR proved that as water repellency appears in soil, exposure to moderately increased temperatures will increase initial water repellency (revealed by CA measurement; Goebel et al., 2011), as well as persistence, as indicated by both, CA and WDPT in our study (Fig. 3). This is especially evident for the subcritically water-repellent soil that showed a high potential for increased persistence in conjunction with the greatest $\mathrm{CA}$ increase among the studied forest soil samples.

The $\mathrm{CA}_{\text {infil }}$ of all three soils were $<90^{\circ}$ after water infiltration, but the subcritically water-repellent and the waterrepellent soil still showed the effect of thermal treatment at $80^{\circ} \mathrm{C}$ (Fig. 4), with $\mathrm{CA} \geq 60^{\circ}$. The data also illustrated the impact of imposed tensions, however the CA differences became small if subcritically water-repellent soil or waterrepellent soil was considered separately for thermal treatments. This demonstrates the amphiphilic character of soil organic matter (i.e., coexistence of hydrophilic and hydrophobic functional groups, Goebel et al., 2011) and the orientation of the amphiphilic compounds with respect to pore space under dry and wet conditions (Doerr et al., 2000; Figs. 3 and 4). At the same time, persistence of SWR was observed for the water- repellent soil, because the $C A_{\text {infil }}$ remained between $75^{\circ}$ to $90^{\circ}$ after infiltration, even for applied pressures of +0.5 and $0 \mathrm{~cm}$ as outlined below.

The RI values of the soils under the applied pressures/tensions for the $25^{\circ} \mathrm{C}$ - and $80^{\circ} \mathrm{C}$-treatments are shown in Fig. 5a. The wettable soil showed no significant increase of the $R I$, after $80^{\circ} \mathrm{C}$-treatment, similar to the results shown in Figs. 3 and 4 for CA and WDPT. Also, in agreement with observed WDPT and CA (Figs. 3 and 4), $R I$ values given in Fig. 5a were larger for water-repellent soil, while the differences between soils treated at 25 and $80^{\circ} \mathrm{C}$ increased with increasing tensions. Interestingly, infiltration was not possible at $-20 \mathrm{~cm}$ for the subcritically water-repellent soil treated at $80^{\circ} \mathrm{C}$. This demonstrates the high sensitivity of the microinfiltrometer to detect non-linear and steeply increasing infiltration resistance for soils at intermediate water repellency under hydraulic tensions greater than a certain value. Fig. 5a suggests further that the $R I$ values for the water-repellent soil with a CA of about $90^{\circ}$ were smaller at slightly positive $(+0.5 \mathrm{~cm})$ or zero pressure compared to the values of the subcritically water-repellent soil (with a CA of about $62^{\circ}$ ) at -20 and $-40 \mathrm{~cm}$. This result outlines that differences in the degree of repellency increase with increasing tension of the infiltrating water. This confirms quantitatively in 

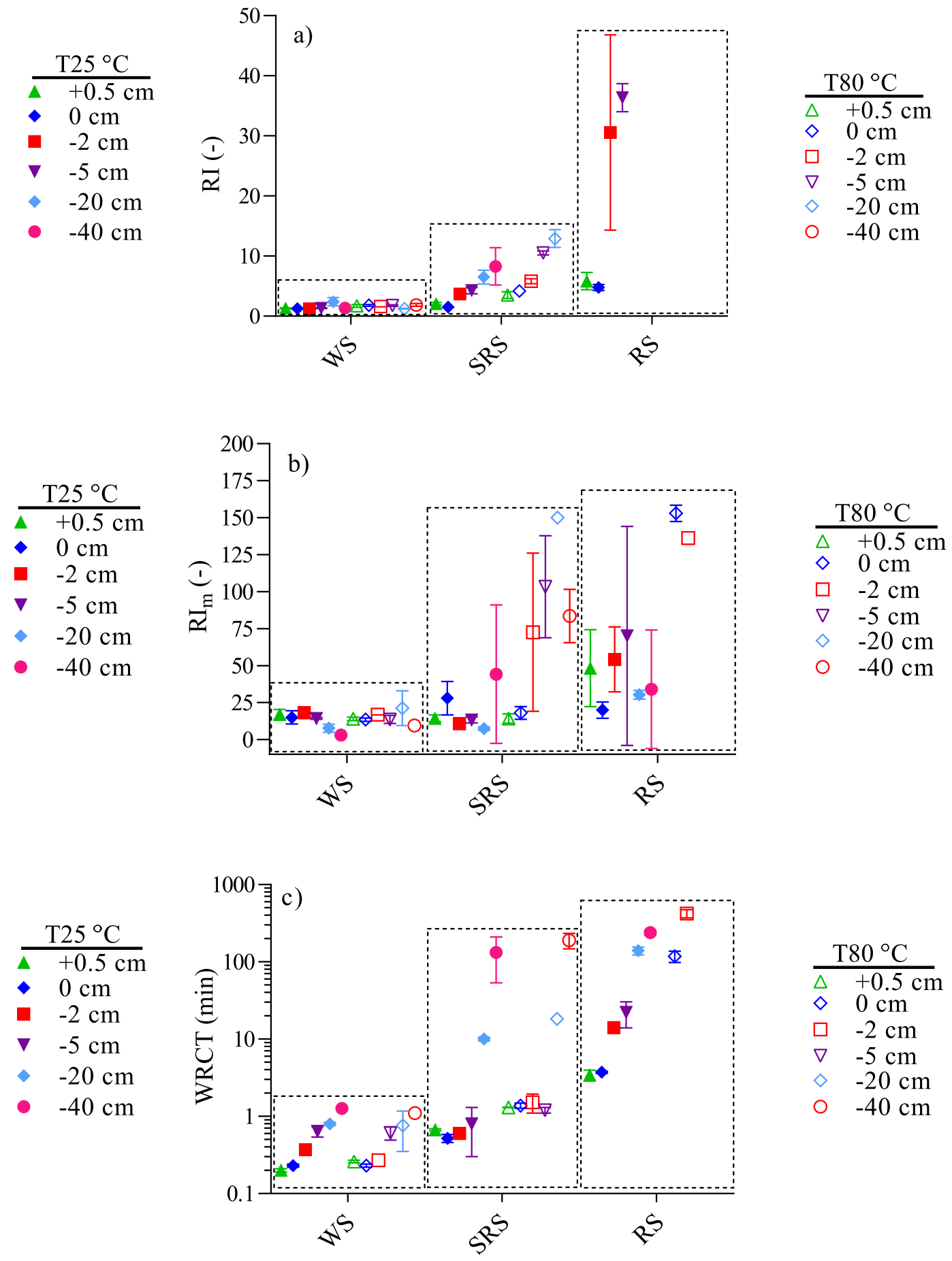

Fig. 5. Extent of SWR of studied soils (WS: wettable soil, SRS: subcritically water-repellent soil, RS: water-repellent soil) quantified by the repellency index, $R I$, (a), modified repellency index, $R I_{m},(\mathrm{~b})$, and extent and persistence of SWR of studied soils using the water repellency cessation time, WRCT, for $25^{\circ} \mathrm{C}$ - and $80^{\circ} \mathrm{C}$ - treatment (c) under different imposed hydraulic pressures/tensions.

the lab the reason for moisture patterns with sharp moisture content boundaries, which may exist in natural soil profiles over weeks and months (Deurer and Bachmann, 2007). A specific roughness (i.e., texture and/or particle microrelief) at the moisture wetting fronts can impede water flow and infiltration through reduced capillary forces and trapping of air in the cavities of the pores when the material itself is hydrophobic (i.e., CA measured at a flat surface of the same material is $\geq 90^{\circ}$ ), which may lead from partially to fully impregnated states (Jonas et al., 2020).
The results of $R I$ measurements for different extents of SWR (Fig. 5a) were consistent with the $R I$ thresholds proposed by Iovino et al. (2018). These results imply that the proposed modifications in the microinfiltrometer construction are promising for its usability within a broad range of hydraulic tensions and different states of SWR. However, we observed some minor under- and overestimations at the applied tensions if $R I$ was considered. For the wettable soil, slight repellency is indicated at $-20 \mathrm{~cm}$ and for the subcritically water-repellent soil, wettability is indicated at $0 \mathrm{~cm}$ tension. Finally, it should be noted 
Development of a universal microinfiltrometer to estimate extent and persistence of soil water repellency

here that for the water-repellent soil treated at $80^{\circ} \mathrm{C}$, infiltration measurements were not possible at any tension, similar to the $25^{\circ} \mathrm{C}$-treatment variant at -20 and $-40 \mathrm{~cm}$, which explains missing data in Fig. 5a.

An alternative method to assess SWR is the characterization through single water infiltration experiments, expressed by the $R I_{m}$ index. These data are shown in Fig. 5b. In comparison, the $R I_{m}$ data showed less regular trends as a function of applied tensions if compared with the $R I$ data (Fig. 5a). This could be due to the insensitivity to define hydrophilic sorptivity, as the reference value based only on water infiltration $\left(S_{w}\right)$ data could be at a different stage of infiltration compared to ethanol $\left(S_{e}\right)$ as the reference state. The latter result might be considered as a disadvantage of the $R I_{m}$ concept so that a representative hydrophilic sorptivity may not be found for soils with a high extent and persistence of water repellency. In general, the trend of data showed the difference in water repellency extent between the studied soils and the applied tensions. However, there is still no classification reference for $R I_{m}$ values to illustrate whether the predictions fit in their own water repellency thresholds or not. This suggests the need for the definition of thresholds as well as for a clear reference of $R I_{m}$ as suggested by Sepehrnia et al. (2016). Alagna et al. (2019) and Sepehrnia et al. $(2016,2017)$ also discussed that $R I_{m}$ may not be an appropriate index to capture SWR across all possible states because both the WRCT and the $R I_{m}$ are obtained from the $I$ versus $\sqrt{t}$ plot of cumulative water infiltration, with the drawbacks discussed above. Furthermore, the WRCT may also be an effect of the volume of water already infiltrated and/or flowing into the soil, hence the wetting bulb size. Additionally, the size and volume of the conducting pores could be different with regards to time and applied pressures/tensions (Beatty and Smith, 2014). Notwithstanding, in comparison to $R I$, the $R I_{m}$ showed slightly greater flexibility in describing the repellency state of water-repellent soil for all applied tensions at $25^{\circ} \mathrm{C}$, as well as 0 and $-2 \mathrm{~cm}$ at $80^{\circ} \mathrm{C}$ after $24 \mathrm{~h}$. Altogether, the results imply that $R I_{m}$ can be a promising parameter to predict the water repellency status of non-repellent $\left(\mathrm{CA}=0^{\circ}\right)$ and subcritically water-repellent $\left(0^{\circ}<\mathrm{CA}<90^{\circ}\right)$ soils through short (3-15 min) infiltration tests, as well water-repellent soils $\left(\mathrm{CA} \geq 90^{\circ}\right)$ using long-term $(24 \mathrm{~h})$ infiltration tests.

No infiltration at pressures lower $+0.5 \mathrm{~cm}$ for water indicates, most likely, high local water repellency persistence at the interfaces (solid-water and air-water), which would result in weak imbibition (Ruspini et al., 2017). In this case, given that water repellency may even inhibit water vapor condensation, local water vapor adsorption may even increase the level of water repellency (Goebel et al., 2004). For the water-repellent soil, infiltration was still observed at tensions of $0 \mathrm{~cm}$ and $-2 \mathrm{~cm}$, but infiltration began with a delay after 158 and 398.5 min, respectively (Table 2). When no infiltration occurred for tensions lower than $-2 \mathrm{~cm}$ (i.e., $-5,-20$, and $-40 \mathrm{~cm}$ ) it showed that the effect of wettability on water infiltration was significantly affected by the tension of the invading water. This meant that the wetting front would not overcome water repellency of the interfaces in the respective pore size classes to create any laminar film or further flow pathways, especially for soils at the transition between subcritically water-repellent and waterrepellent soils.

The WRCT of the studied soils, which considers the extent and persistence of SWR for the applied thermal treatments $\left(25^{\circ} \mathrm{C}\right.$ and $\left.80^{\circ} \mathrm{C}\right)$ is presented in Fig. $5 \mathrm{c}$. It can be seen that the WRCT was very sensitive to the applied tensions and was greatest for water-repellent samples (Fig. 5c). However, WRCT values of the wettable and subcritically water-repellent soils treated at $25^{\circ} \mathrm{C}$ were similar to those of the $80^{\circ} \mathrm{C}$-treated soils. For the $80^{\circ} \mathrm{C}$-heated water-repellent soil, however, WRCT increased at low tensions (i.e., 0 and $-2 \mathrm{~cm}$ ). This may indicate a more stable modification in interface chemical composition towards greater rigidity of the arrangement of functional groups compared to the subcritically water-repellent soil.

\section{Extent and persistence of soil water repellency in relation to interface chemical composition}

The main compounds of all interfaces were $\mathrm{O}$ and $\mathrm{C}$, followed by $\mathrm{Si}, \mathrm{Al}$, and some Fe. Further, traces $(<0.2$ at.- $\%)$ of $\mathrm{Na}, \mathrm{Ca}, \mathrm{K}$, and $\mathrm{Mg}$ were detected (data not shown). Interface $\mathrm{O} / \mathrm{C}$ ratio of air-dry soils increased from water-repellent to subcritically water-repellent to wettable soil (Woche et al., 2017). There was a tendency for the $80^{\circ} \mathrm{C}$-treatment to have a slightly decreased $\mathrm{O} / \mathrm{C}$ ratio for the water-repellent soil, while no measurable effect was observed for the subcritically waterrepellent and the wettable soils (Table 4). A decrease in $\mathrm{O} / \mathrm{C}$ ratio along with increasing $\mathrm{CA}$ after heat treatment of sandy soil (sand content $>75 \%$ ) has been observed before (Bachmann et al., 2020; Diehl et al., 2014; Gaj et al., 2019). Thus, the distinctly smaller sand content of the subcritically water-repellent and the wettable material (Table 1) may explain the different behaviour. Pooling of all samples identified a tendency of $\mathrm{O} / \mathrm{C}$ ratio of air-dry soils to be slightly smaller than for shock-frozen and freeze-dried soils ( $1.66 \pm 0.57$ and $1.81 \pm 0.78$, respectively), but the difference was not significant $(p>0.05)$.

However, $\mathrm{CA}$ as well as $\mathrm{CA}_{\text {infil }}$ (measured after infiltration) and $\mathrm{O} / \mathrm{C}$ ratios of all tested soils fitted very well within the general regression of $\mathrm{O} / \mathrm{C}$ ratio vs. $\mathrm{CA}$, derived from a broad range of different materials (Woche et al., 2017). Within the samples tested, a significant negative linear relationship between $\mathrm{CA}$ and $\mathrm{O} / \mathrm{C}$ ratio was observed for both air-dry $\left(R^{2}=\right.$ $0.80, p<0.05)$ as well as shock-frozen and freeze-dried samples $\left(R^{2}=0.72, p<0.05\right.$; Fig. 6a). Further, the values of $S_{w}$ were found to be positively related to the interface $\mathrm{O} / \mathrm{C}$ ratio of shock-frozen and freeze-dried samples. This was most apparent at $-2 \mathrm{~cm}$ and $-5 \mathrm{~cm}$ infiltrating tensions, where a significant positive relationship was observed $\left(R^{2}=0.99, p<0.001\right.$ and $R^{2}$ $=0.86, p<0.05$, respectively; Fig. 6b). Therefore, we confirmed the hypothesis that the general relation between the water repellency parameters (evaluated at $-2 \mathrm{~cm}$ ) are also valid for greater tension values.

The results revealed that the reduced infiltration at higher tensions was governed by the same wettability parameters. In other words, the reduced infiltration was caused by water repellency and not by additional effects caused by the technical setup of the proposed microinfiltrometer. This is a very important finding that can be utilized to build up hydraulic models for SWR. Along with decreasing CA from water repellent to subcritically water-repellent and wettable soils, $\mathrm{C}$ speciation indicated decreasing amounts of non-polar $\mathrm{C}-\mathrm{C}$ and $\mathrm{C}-\mathrm{H}$ species, as confirmed by decreasing $\mathrm{C}_{\mathrm{np}}$ contents derived from the fit of the survey $\mathrm{C} 1 \mathrm{~s}$ peak. For $80^{\circ} \mathrm{C}$-treated waterrepellent soil, the content of $\mathrm{C}-\mathrm{C}$ and $\mathrm{C}-\mathrm{H}$ species and $\mathrm{C}_{\mathrm{np}}$ increased as CA increased (Table 3, Figs. 4 and 6). However, in agreement with observed $\mathrm{O} / \mathrm{C}$ ratios, for subcritically waterrepellent and wettable soils, the content of $\mathrm{C}-\mathrm{C}$ and $\mathrm{C}-\mathrm{H}$ species and $\mathrm{C}_{\mathrm{np}}$ compounds was similar for the $25^{\circ} \mathrm{C}$ and $80^{\circ} \mathrm{C}$ treatments, despite a distinct increase in CA for the subcritically water- repellent soil (Table 3, Figs. 4 and 6).

Benito et al. (2019) evaluated persistence of SWR using WDPT. They concluded that water repellency exhibited a significant positive correlation with $\mathrm{C}$ content and $\mathrm{C} / \mathrm{N}$ ratio, 
Table 4. Interface $\mathrm{O} / \mathrm{C}$ and $\mathrm{C} / \mathrm{N}$ ratio as derived from XPS analysis for the $25^{\circ} \mathrm{C}$ - and the $80^{\circ} \mathrm{C}$-treated soils (WS: wettable soil, SRS: subcritically water-repellent soil, RS: water-repellent soil). Further, the amounts of non-polar $\mathrm{C}-\mathrm{C}, \mathrm{C}-\mathrm{H}$ species (derived from fit of the $\mathrm{C}$ 1s detail scans) and the amounts of polar $\left(\mathrm{C}_{\mathrm{p}}\right)$ and non-polar $\left(\mathrm{C}_{\mathrm{np}}\right)$ compounds (derived from fit of the survey $\mathrm{C}$ 1s peak) and their ratio $\left(\mathrm{C}_{\mathrm{np}} / \mathrm{C}_{\mathrm{p}}\right)$ are given. Data, presented as mean \pm standard deviation, refer to spectra recorded on air-dry soils.

\begin{tabular}{|c|c|c|c|c|c|c|}
\hline & $\mathrm{O} / \mathrm{C}(-)$ & $\mathrm{C} / \mathrm{N}(-)$ & $\mathrm{C}-\mathrm{C}, \mathrm{C}-\mathrm{H}($ at.- $\%)$ & $\mathrm{C}_{\mathrm{p}}$ (at.-\%) & $\mathrm{C}_{\mathrm{np}}($ at.- $\%)$ & $\mathrm{C}_{\mathrm{np}} / \mathrm{C}_{\mathrm{p}}(-)$ \\
\hline & \multicolumn{6}{|c|}{$25^{\circ} \mathrm{C}$} \\
\hline WS & $2.40( \pm 0.1)$ & $20.30( \pm 2.20)$ & $9.20( \pm 1.60)$ & $14.60( \pm 2.80)$ & $8.30( \pm 2.70)$ & $0.60( \pm 0.30)$ \\
\hline SRS & $1.50( \pm 0.3)$ & $27.10( \pm 2.00)$ & $14.30( \pm 3.40)$ & $18.10( \pm 2.60)$ & $14.50( \pm 2.50)$ & $0.80( \pm 0.10)$ \\
\hline \multirow[t]{2}{*}{ RS } & $1.20( \pm 0.1)$ & $26.10( \pm 1.50)$ & $17.10( \pm 1.80)$ & $19.50( \pm 0.20)$ & $19.30( \pm 1.00)$ & $1.00(0.00)$ \\
\hline & \multicolumn{6}{|c|}{$80^{\circ} \mathrm{C}$} \\
\hline WS & $2.3( \pm 0.1)$ & $18.80( \pm 3.70)$ & $10.0( \pm 0.90)$ & $11.10( \pm 0.90)$ & $13.20( \pm 0.30)$ & $1.20( \pm 0.10)$ \\
\hline SRS & $1.6( \pm 0.1)$ & $33.40( \pm 4.00)$ & $15.2( \pm 0.50)$ & $16.40( \pm 0.90)$ & $15.80( \pm 0.90)$ & $1.0( \pm 0.10)$ \\
\hline RS & $1.0( \pm 0.3)$ & $31.40( \pm 3.40)$ & $21.70( \pm 4.80)$ & $19.80( \pm 3.60)$ & $23.30( \pm 4.30)$ & $1.20(0.00)$ \\
\hline
\end{tabular}
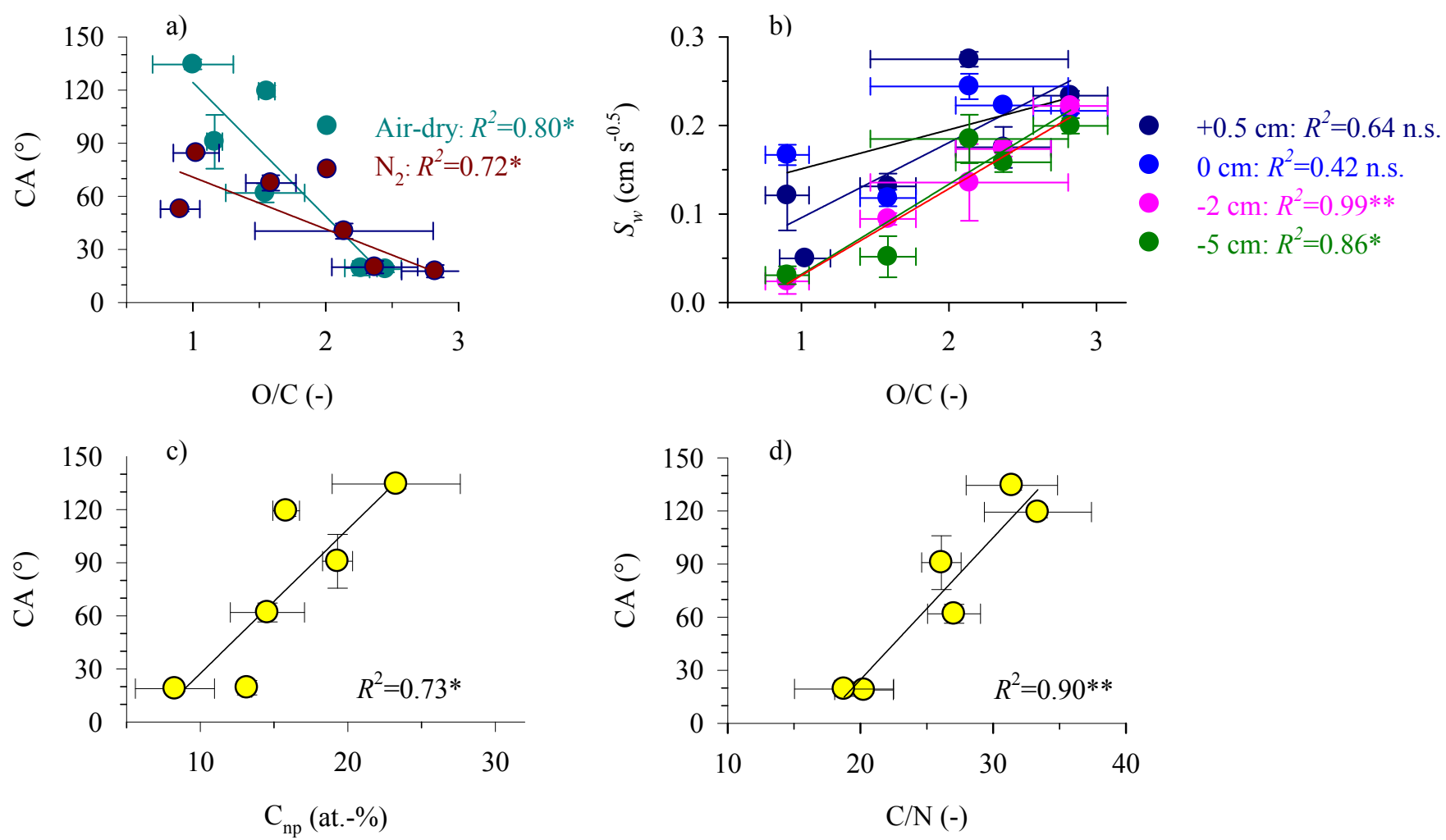

Fig. 6. Relationship between interface $\mathrm{O} / \mathrm{C}$ ratio and contact angle (CA) for air-dry and shock-frozen and freeze-dried $\left(\mathrm{N}_{2}\right)$ samples $(a)$, relationship between $\mathrm{O} / \mathrm{C}$ ratio of shock-frozen and freeze-dried $\left(\mathrm{N}_{2}\right)$ samples and water sorptivity $\left(S_{w}\right)$ for pressures applied (b), relationship between $\mathrm{CA}$ and the amount of non-polar $\mathrm{C}$ compounds $\left(\mathrm{C}_{\mathrm{np}} ; \mathrm{c}\right)$, and relationship between $\mathrm{CA}$ and interface $\mathrm{C} / \mathrm{N}$ ratio $(\mathrm{d})$. The lines represent linear regression fits. Significance levels: $* p<0.05 ; * *<0.01$.

regardless if samples were air-dried or field-moist. Bulk and interface $\mathrm{C}$ content showed the same trend, i.e., decreasing contents from water-repellent to subcritically water-repellent and wettable soil. Total interface $\mathrm{C}$ content of the $25^{\circ} \mathrm{C}$ and the $80^{\circ} \mathrm{C}$ treated soils was significantly positively correlated with CA $\left(R^{2}=0.77, p<0.05\right)$. Based on $\mathrm{C}$ speciation and the basic fit of the survey $\mathrm{C}$ 1s peaks, the content of non-polar $\mathrm{C}-\mathrm{C}, \mathrm{C}-\mathrm{H}$ species and non-polar $\mathrm{C}$ compounds $\left(\mathrm{C}_{\mathrm{np}}\right)$, respectively, were indicated to determine wetting properties $\left(R^{2}=0.84, p<0.001\right.$, and $R^{2}=0.73, p<0.05$, respectively). Correlations were also valid for $\mathrm{CA}$ determined after five seconds $\left(\mathrm{C}-\mathrm{C} / \mathrm{C}-\mathrm{H}: R^{2}=\right.$ $\left.0.80, p<0.05 ; \mathrm{C}_{\mathrm{np}}: R^{2}=0.76, p<0.05\right)$, supporting the relation between sessile drop CA vs. the amount of non-polar $\mathrm{C}$ species and $\mathrm{C}_{\mathrm{np}}$ within the interface layer. In line with Benito et al. (2019), the interface $\mathrm{C} / \mathrm{N}$ ratio was significantly positively correlated with CA $\left(R^{2}=0.90, p<0.05\right)$.

\section{Rating of the microinfiltrometer signals}

We showed that the effect of SWR on water infiltration depends on the applied hydraulic pressure/tension. As a consequence, the proposed microinfiltrometer can measure the effect of pressure/tension-dependent water repellency. It allows the relation between the infiltration behaviour of liquids in waterrepellent soil and the respective penetration dynamics of several liquids (i.e., water and ethanol) to be identified, so that water repellency-based parameters can be derived. Further information can be obtained from liquid infiltration using a microinfiltrometer if the RI is compared with WDPT and sessile drop CA. Although CA and WDPT characterize soil wetting properties (Bachmann et al., 2003; Dekker and Ritsema, 1994; Hallett, 2007), neither CA nor WDPT gives information on real water flow because additional parameters like pore-size-dependent 
wettability determine the infiltration process. The $R I$ provides this information and could possibly be used with an adapted infiltrometer design in the field to detect small-scale variability, i.e., in and around macropores or aggregate surfaces. In addition, valuable information can be derived from cumulative infiltration with time. For example, Fig. 7a shows cumulative water infiltration under $-2 \mathrm{~cm}$ tension. From Fig. $7 \mathrm{~b}$, the cumulative infiltration curve for the subcritically water-repellent soil, treated at $80^{\circ} \mathrm{C}$, consisted of three phases. These phases became more distinct as SWR increased. These phases are postulated to show SWR persistence (phase I), the transition state (phase II) which simultaneously reflects changes in the orientation of functional groups with respect to pore space and pore size switch to allow water infiltration, and the nearly stationary steady-state infiltration (phase III). The infiltration rate versus time evaluated with this microinfiltrometer could be applied to investigate wetting front propagation in soil aggregates (LeedsHarrison, 1994, 1997; Wang et al., 2000) at the micro-scale (Hallett and Young, 1999; Hallett et al., 2001; Mao et al., 2019). This allows progress in small-scale detection of spatial variability of water repellency as suggested by Mao et al., (2019) and Rodríguez-Alleres and Benito (2011). Since the infiltration front is not infinitely small, the transition must be regarded as a complicated process of several overlaying processes (Bauters et al., 2000; Dekker and Ritsema, 2000), which
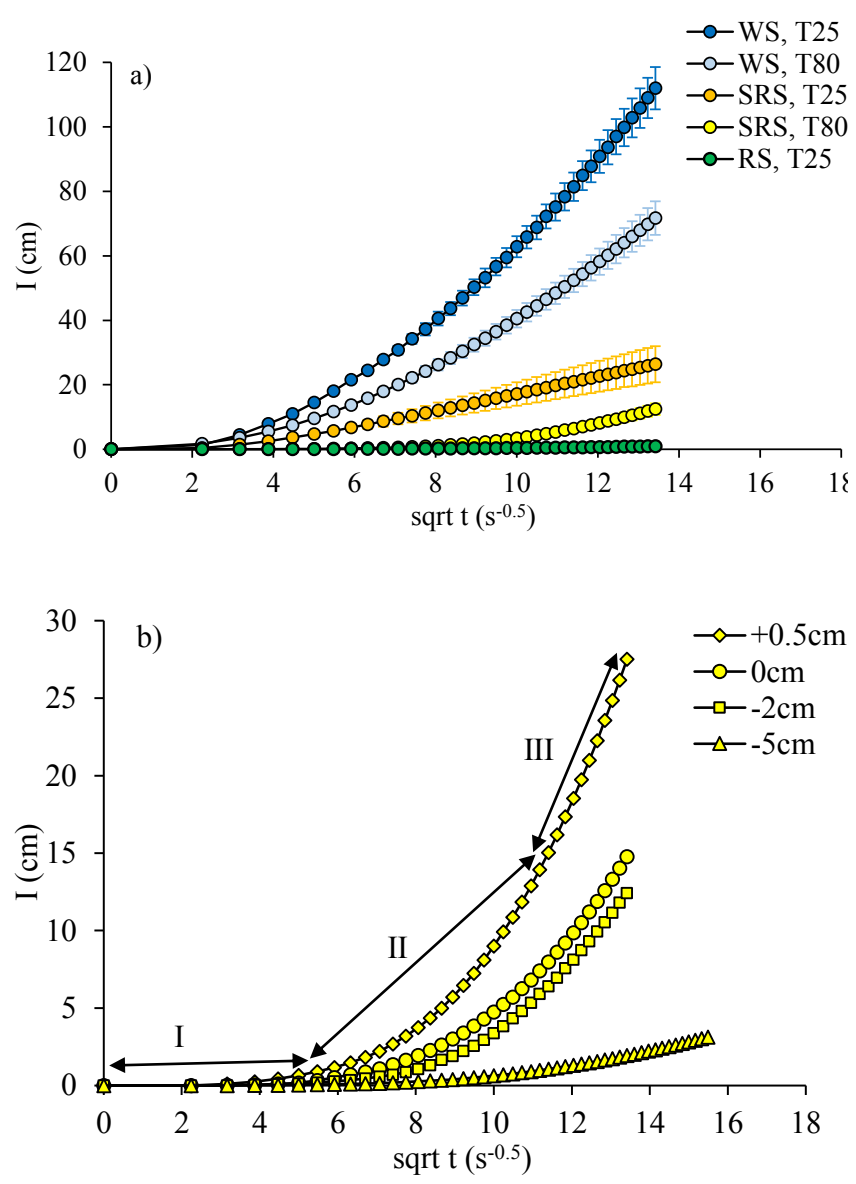

Fig. 7. Cumulative water infiltration at a $-2 \mathrm{~cm}$ tension for the studied soils (WS: wettable soil, SRS: subcritically water-repellent soil, RS: water-repellent soil) treated at 25 and $80^{\circ} \mathrm{C}$ (a), magnified cumulative infiltration curve of the SRS treated at $80^{\circ} \mathrm{C}$ under different hydraulic pressures/tensions $(+0.5,0,-2$, and $-5 \mathrm{~cm})$, with three different infiltration phases marked (I, II, III; b). explains the extended transition zone of the hockey-stick behaviour between the linear infiltration rates of phase I and III. This will be evaluated in further research exploring soil CA. Generally, the microinfiltrometer signal displays the smallscale transition in the wetting zone caused by the loss of water repellency depending on several factors like aggregate size, the respective location of water repellent zones such as hydrophobic coatings under different tensions, and the energy status of the soil water (De Rooij, 2000; Deurer and Bachmann, 2007).

\section{CONCLUSIONS}

We designed an improved microinfiltrometer to allow for long-time measurements at a broad range of tensions with a standardized tip that allowed for high rates of liquid transport for different liquids. The modified microinfiltrometer worked well in water and ethanol infiltration tests. Studies were conducted with three sandy soils with different initial wettability that were thermally treated at $25^{\circ} \mathrm{C}$ and $80^{\circ} \mathrm{C}$. Infiltration measurements could be made for a broad range of hydraulic conditions $(+0.5,0,-2,-5,-20$, and $-40 \mathrm{~cm})$. The suggested microinfiltrometer modifications are i) to use a glass tube with $3 \mathrm{~mm}$ inner diameter to make both water and ethanol infiltrations possible at constant flow rate and prevent a noisy signal during the test, ii) to cover the microinfiltrometer with Plexiglas hoods to prevent evaporation from tip and reservoir, iii) to use degassed ultrapure water to run tensions higher than $-5 \mathrm{~cm}$, and iv) to use a $15 \mu \mathrm{m}$-nylon mesh to enclose the tip in order to prevent air bubble formation in the system. It is thus expected that this microinfiltrometer also works for soils with finer texture. Our study led to the following conclusions:

- $\quad$ XPS data and the evaluated SWR indices ( $R I, R I_{m}$, and WRCT) demonstrated infiltration tests $-2 \mathrm{~cm}$ tension provides valuable information for different aspects of water repellency, like extent and persistence. In this respect it is possible to analyse water infiltration also for hydrophobic soils $\left(\mathrm{CA} \geq 90^{\circ}\right)$ through long-time tests $(24 \mathrm{~h})$, which may allow a better characterization of sorptivity of hydrophobic soils.

- Experimental data derived from the proposed microinfiltrometer setup may support the development of micro-hydraulic models to simulate infiltration at the pore scale under different boundary conditions like the tension of the infiltration water.

- Thermal treatment effects on wetting properties and sorptivity illustrated a sufficient sensitivity of the microinfiltrometer to detect changes in water repellency caused by the chemical composition of the particle interfaces while all other factors (organic carbon content, pore shape) remained constant. This suggests that further modifications of SWR; e.g., caused by changing climatic conditions like extended droughts or slightly increasing soil temperatures, may be detected with respect to their micro-hydraulic relevance. A modified wettability of bulk soil or soil aggregates might be relevant for complex environmental issues like soil erosion, available water or /and contaminant transport.

- Interface $\mathrm{O} / \mathrm{C}$ ratio and the amount of non-polar carbon compounds of the outermost soil particle interface layer explains the level of water repellency as well as the infiltration behaviour with respect to extent and persistence of SWR which was shown in this paper for the first time. Further, the positive relationship (in trend and significant, respectively) between water sorptivity and interface $\mathrm{O} / \mathrm{C}$ ratio of shock-frozen and freeze-dried samples additionally proves the governing role of the interface chemical composition for all soil processes. 
Acknowledgements. We thank the Alexander von Humboldt Foundation for financial support of this project and donating post-doctoral fellowship to first author. We acknowledge Martin Volkmann, Moritz Rahlfs, Hanna Böhme, Stephanie Günther, and Henrik Redweik for their help with soil sampling and preparing stuff. We appreciate Professor Paul Hallett for his constructive comments and direct communication about microinfiltrometer tips and improving the English language of the text. Furthermore, we appreciate the feedback of anonymous reviewers whose constructive comments improved the article.

\section{REFERENCES}

Alagna, V., Iovino, M., Bagarello, V., Mataix-Solera, J., Lichner, L., 2019. Alternative analysis of transient infiltration experiment to estimate soil water repellency. Hydrol. Process., 33, 661-674.

Bachmann, J., Woche, S.K., Goebel, M-O., Kirkham, M.B., Horton, R., 2003. Extended methodology for determining wetting properties of porous media. Water Resour. Res., 39, 1353.

Bachmann, J., Deurer, M., Arye, G., 2007. Water-repellent soil: Development of a contact angle-dependent water-retention model. Vadose Zone J., 6, 436-445.

Bachmann, J., Söffker. S., Sepehrnia, N, Goebel, M.-O., Woche, S.K., 2020. The effect of temperature and wettingdrying cycles on soil wettability: Dynamic molecular restructuring processes at the solid-water-air interface. (In preparation).

Bauters, T.W.J., Steenhuis, T.S., DiCarlo, D.A., Nieber, J.L., Dekker, L.W. Ritsema, C.J., Parlange, J.-Y., Haverkamp, R., 2000. Physics of water repellent soils. J. Hydrol., 231-232, 233-243.

Beatty, S.M., Smith, J.E., 2014. Infiltration of water and ethanol solutions in water repellent post wildfire soils. J. Hydrol., 514, 233-248.

Benito, E., Varela, E., Rodríguez-Alleres, M., 2019. Persistence of water repellency in coarse-textured soils under various types of forests in NW Spain. J. Hydrol. Hydromech., 67, 129-134.

Clothier, B.E., Vogeler, I., Magesan, G.N., 2000. The breakdown of water repellency and solute transport through a hydrophobic soil. J. Hydrol., 231-232, 255-264.

Cosentino, D., Hallett, P.D., Michel, J.C., Chenu, C., 2010. Do different methods for measuring the hydrophobicity of soil aggregates give the same trends in soil amended with residue? Geoderma, 159, 221-227.

De Rooij, GH., 2000. Modeling fingered flow of water in soils owing to wetting front instability: a review. J. Hydrol., 231232, 277-294.

Decagon, 2007. Minidisk Infiltrometer User's Manual. Version 6. Decagon Devices, Inc., Pullman.

Dekker, L.W., Ritsema, C.J., 1994. How water moves in a water repellent sandy soil. I. Potential and actual water repellency. Water Resour. Res., 30, 2507-2517.

Dekker, L.W., Ritsema, C.J., 2000. Wetting patterns and moisture variability in water repellent Dutch soils. J. Hydrol., 231-232, 148-164.

Dekker, L.W, Doerr, S.H, Oostindie, K., Ziogas, A.K., Ritsema, C.J., 2001. Water repellency and critical soil water content in a dune sand. Soil Sci. Soc. Am. J., 65, 1667-1674.

Dekker, L.W., Oostindie, K., Ritsema, C.J., 2005. Exponential increase of publications related to soil water repellency. Aust. J. Soil Res., 43, 403-441.

Deurer, M., Bachmann, J., 2007. Modeling water movement in heterogeneous water-repellent soil: 2 . A conceptual numerical simulation. Vadose Zone J., 6, 446-457.

Diehl, D., Schneckenburger, T., Krüger, J., Goebel, M.-O., Woche, S.K., Schwarz, J., Shchegolikhina, A., Lang, F., Marschner, B., Thiele-Bruhn, S., Bachmann, J., Schaumann, G.E., 2014. Effect of multivalent cations, temperature and aging on soil organic matter interfacial properties. Environ. Chem., 11, 709-718.

Doerr, S.H., Shakesby, R.A., Walsh, R.P.D., 2000. Soil water repellency: its causes characteristics and hydrogeomorphological significance. Earth-Sci. Rev., 51, 33-65.

Evonik, 2000. Stress Crack and Chemical Resistance. Darmstadt, Germany.

Gaj, M., Lamparter, A., Woche, S.K., Bachmann, J., McDonnell, J.J., Stange, C.F., 2019. The role of matric potential, solid interfacial chemistry, and wettability on isotopic equilibrium fractionation. Vadose Zone J., 18. DOI: 10.2136/vzj2018.04.0083

Goebel, M-O, Bachmann, J, Woche, S.K, Fischer, W.R, Horton, R., 2004: Water potential and aggregate size effects on contact angle and surface energy. Soil Sci. Soc. Am. J., 68, 383-393.

Goebel, M.-O., Bachmann, J., Reichstein, M., Janssens I.A., Guggenberger, G., 2011. Soil water repellency and its implications for organic matter decomposition - is there a link to extreme climatic events? Glob. Change Biol., 17, 26402656.

Goebel, M.O., Woche, S.K., Abraham, P.M., Schaumann, G.E., Bachmann, J., 2013. Water repellency enhances the deposition of negatively charged hydrophilic colloids in a watersaturated sand matrix. Colloids Surf. A, 431, 150-160.

Gordon, D.C., Hallett, P.D., 2014. An automated microinfiltrometer to measure small-scale soil water infiltration properties. J. Hydrol. Hydromech., 62, 248-252.

Hallett, P.D., 2007. An introduction to soil water repellency. In: Gaskin, R.E. (Ed.): Adjuvants for Agrochemicals. Hand Multimedia, Christchurch, New Zealand, 9 p.

Hallett, P.D., Young, I.M., 1999. Changes to water repellence of soil aggregates caused by substrate-induced microbial activity. Eur. J. Soil Sci., 50, 35-40.

Hallett, P.D., Baumgartl, T., Young, I.M., 2001. Subcritical water repellency of aggregates from a range of soil management practices. Soil Sci. Soc. Am. J., 65, 184-190.

Hallett, P.D., Gordon, D.C., Bengough, A.G., 2003. Plant influence on rhizosphere hydraulic properties: direct measurements using a miniaturized infiltrometer. New Phytol., 157, 597-603.

Iovino, M., Pekárová, P., Hallett, P.D., Pekár, J., Lichner, L., Mataix-Solera, J., Alagna, V., Walsh, R., Raffan, A., Schacht, K., Rodný, M., 2018. Extent and persistence of soil water repellency induced by pines in different geographic regions. J. Hydrol. Hydromech., 66, 360-368.

Johnson, M.S., Lehmann, J., Steenhuis, T.S., Oliveira, L.V., Fernandes, E.C.M., 2005. Spatial and temporal variability of soil water repellency of Amazonian pastures. Aust. J. Soil Res., 43, 319-326.

Jonas, A.M., Cai. R., Vermeyen, R., Nysten, B., Vanneste, M., Smet, D.D., Glinel, K., 2020. How roughness controls the water repellency of woven fabrics. Mater. Des., 187, 108389.

Leeds-Harrison, P.B., Youngs, E.G., 1997. Estimating the hydraulic conductivity of aggregates conditioned by different tillage treatments from sorption measurements. Soil Till. Res., 41, 141-147.

Leeds-Harrison, P.B., Youngs, E.G., Uddin, B., 1994. A device 
for determining the sorptivity of soil aggregates. Eur. J. Soil Sci., 45, 269-272.

Leelamanie, D.A.L., Karube, J., Yoshida, A., 2008. Characterizing water repellency indices: Contact angle and water drop penetration time of hydrophobized sand. J. Soil Sci. Plant Nutr., 54, 179-187.

Letey, J., Carrillo, M.L.K., Pang, X.P., 2000. Approaches to characterize the degree of water repellency. J. Hydrol., 231232, 61-65.

Li, X., Chang, S.S.X., Salifu, K.F., 2014. Soil texture and layering effects on water and salt dynamics in the presence of a water table: a review. Environ. Rev., 22, 41-50.

Lichner, L., Hallett, P.D., Drongova, Z., Czachor, H., Kovacik, L., Mataix-Solera, J., Homolak, M., 2013. Algae influence the hydrophysical parameters of a sandy soil. Catena, 108, $58-68$.

Lichner, L., Felde, V.J.M.N.L., Büdel, B., Leue, M., Gerke, H.H., Ehlerbrock, R.H., Kollár, J., Rodný, M., Šurda, P., Fodor, N., Sándor, R., 2018. Effect of vegetation and its succession on water repellency in sandy soils. Ecohydrology, 11, e1991.

Mao, J., Nierop, K.G.J., Dekker, S.C., Dekker, L.W., Chen, B., 2019. Understanding the mechanisms of soil water repellency from nanoscale to ecosystem scale: a review. J. Soils Sediments, 19, 171-185.

Muehl, G.J.H., Ruehlmann, J., Goebel, M.-O., Bachmann, J., 2012. Application of confocal laser scanning microscopy (CLSM) to visualize the effect of porous media wettability on unsaturated pore water configuration. J. Soils Sediments, $2,75-85$.

Orfánus, T., Dlapa, P., Fodor, N., Rajkai, K., Sándor, R., Nováková, K., 2014. How severe and subcritical water repellency determines the seasonal infiltration in natural and cultivated sandy soils. Soil Till. Res., 135, 49-59.

Philip, J.R., 1957. The theory of infiltration: 1 . The infiltration equation and its solution. Soil Sci., 83, 345-357.

R Core Team, 2013. R: A language and environment for statistical computing. R Foundation for Statistical Computing, Vienna, Austria. URL http://www.R-project.org/.
Rodríguez-Alleres, M., Benito, E., 2011. Spatial and temporal variability of surface water repellency in sandy loam soils of NW Spain under Pinus pinaster and Eucalyptus globulus plantations. Hydrol Process., 25, 3649-3658.

Ruspini, L.C., Farokhpoor, R., Øren, P.E., 2017. Pore-scale modeling of capillary trapping in water-wet porous media: A new cooperative pore-body filling model. Adv. Water Resour., $108,1-14$.

Sepehrnia, N., Hajabbasi, M.A., Afyuni, M., Lichner, L., 2016. Extent and persistence of water repellency in two Iranian soils. Biologia, 71, 1137-1143.

Sepehrnia, N., Hajabbasi, M.A., Afyuni, M., Lichner, L., 2017. Soil water repellency changes with depth and relationship to physical properties within wettable and repellent soil profiles. J. Hydrol. Hydromech., 65, 99-104.

Thieme, L., Graeber, D., Kaupenjohann, M., Siemens, J., 2016. Fast-freezing with liquid nitrogen preserves bulk dissolved organic matter concentrations, but not its composition. Biogeosciences, 13, 4697-4705.

Tillman, R.W., Scotter, D.R., Wallis, M.G., Clothier, B.E., 1989. Water-repellency and its measurement by using intrinsic sorptivity. Aust. J. Soil Res., 27, 637-644.

Tschapek, M., 1984. Criteria for determining the hydrophilicity-hydrophobicity of Soils. J. Plant Nutr. Soil Sci., 137-149.

Wang, Z., Wu, Q.J., Wu, L., Ritsema, C.J., Dekker, L.W., Feyen, J., 2000. Effects of soil water repellency on infiltration rate and flow instability. J. Hydrol., 231-232, 265-276.

Wenzel, R.N., 1936. Resistance of solid surfaces to wetting by water. Ind. Eng. Chem., 28, 988-994.

Woche, S.K., Goebel, M.-O., Mikutta, R., Schurig, C., Kaestner, M., Guggenberger, G., Bachmann, J., 2017. Soil wettability can be explained by the chemical composition of particle interfaces - An XPS study. Sci. Rep., 7, 42877.

Zhang, R., 1997. Determination of soil sorptivity and hydraulic conductivity from the disk infiltrometer. Soil Sci. Soc. Am. J., 61, 1024-1030.

Received 24 March 2020

Accepted 20 August 2020 